\begin{tabular}{|c|l|}
\hline Title & $\begin{array}{l}\text { The possibility of sustainable pest management by introducing bio-diversity : simulations of pest mite outbreak and } \\
\text { regulation }\end{array}$ \\
\hline Author(s) & Tsuji, Nobuyuki; Chittenden, A nthony R.; Ogawa, Takuya; Takada, Takenori; Zhang, Y an-X uan; Saito, Y utaka \\
\hline Citation & $\begin{array}{l}\text { Sustainability Science, 6(1), 97-107 } \\
\text { https:/doi.org/10.1007/311625-010-0113-1 }\end{array}$ \\
\hline Issue Date & 2011-01 \\
\hline Doc URL & http://hdl.handle.net/2115/46797 \\
\hline Rights & The original publication is available at www.springerlink.com \\
\hline Type & article (author version) \\
\hline File Information & SS6-1_97-107.pdf \\
\hline
\end{tabular}

Instructions for use 


\title{
The possibility of sustainable pest management by introducing bio-diversity: simulations of pest mite outbreak and regulation
}

Nobuyuki Tsuji, Anthony R. Chittenden, Takuya Ogawa, Yan Xuan Zhang, Takenori Takada, Yutaka Saito

\begin{abstract}
Since the late 1980s, spider mite pests have caused serious damage to many moso bamboo (Phyllostachys pubescens) forests in China's Fujian province. The culms of this plant are an essential component of the building and handicraft industries and its shoots are a prized food item in many Asian countries. Furthermore, bamboo forests play an important soil conservation role in mountainous areas. We examined the pest mite outbreaks in several Fujian moso bamboo plantations, and could show that a change in cultivation style from polyculture (a kind of mixed forest) to monoculture was the prime reason for the outbreaks. We then tried to identify factors that resulted from such a cultivation change. Using a systems simulation approach, we determined that systems consisting of one common predator, two host-specific pest mites on different host plants frequently became stable when the pest mites were at low density, meaning that at least two plants, moso bamboo and Chinese silvergrass are necessary to maintain stable predator-prey interactions in moso forests. This finding clearly indicates that bio-diversity, even when it consists of only 2 plants and 3 mite species as in this study, is
\end{abstract}


necessary for the sustainable regulation of large-scale forests, such as moso bamboo plantations.

Nobuyuki Tsuji, Anthony R. Chittenden

Sustainability Governance Project (SGP), the Center for Sustainability Science,

Hokkaido University, Sapporo 060-0809, Japan.

Takuya Ogawa, Yutaka Saito (Corresponding author)

Laboratory of Animal Ecology, Research Faculty of Agriculture, Hokkaido University, 060-8589, Sapporo, Japan.

e-mail: yutsat@res.agr.hokudai.ac.jp

Yan Xuan Zhang

Institute of Plant Protection, Fujian Academy of Agriculture, Fuzhou, China.

Takenori Takada

Lab. Mathematical Ecology, Graduate School of Earth Environmental Science, Hokkaido University, 060-0810, Sapporo, Japan.

Key words: moso bamboo, Chinese silvergrass, tetranychid, phytoseiid, Predator-prey interaction, numerical simulation, Typhlodromus bambusae, Stigmaeopsis nanjingensis, Stigmaeopsis miscanthi

\section{Introduction}

More than half a century has elapsed since the majority of the world's agricultural systems switched to monoculture practices in order to attain greater yields. 
Characterized by artificial fertilizers, pesticides and machinery, modern monoculture is wholly dependent on continual inputs of cheap chemical compounds and energy, both of which are ultimately derived from fossil fuels. If, as is widely anticipated, we are unable to depend upon such limited resources, then our food production is no longer sustainable.

Chemical pesticides have an important role to play in modern agriculture and have undoubtedly contributed to the increased yields we have enjoyed over the last 70 years. However, coupled with the introduction of monoculture practices, the amount of pesticides used in agriculture has increased to an astonishing 3 million metric tons annually (Pimentel 2004). This has had an array of adverse effects on bio-diversity and human health (Carson 1962, Colborn et al. 1966). Furthermore, the rapid development of pesticide resistant pest strains has rendered many chemical compounds ineffective (Flexner et al. 1995; Tsagkarakou et al. 1996; Beers et al. 1998). This has lead to the concepts of biological control and integrated pest management (IPM) being proposed, and technical developments continue to unfold. Despite several successful examples of "classical biological control" in which introduced natural enemies could regulate invasive pests (Ruberson et al. 1998; Weeden et al. 2008), most attemp ts use artificially mass-produced natural enemies as agents of pest control, which like pesticides, inevitably require considerable energy resources to produce.

Recently, the concept of "conservation biological control" using "banker plants" as nurseries of natural enemies was proposed (Tscharntke et al. (2007); Osborne and Barrett (2005)). This is an old-yet-new concept that considers endemic natural 
enemies that have coevolved with endemic pest species to be potentially important pest regulation agents in endemic vegetation. The paradigm shift from polyculture to monoculture agriculture is thought to be a critical factor behind the disappearance of these native natural enemies from agricultural fields, which may be one of the reasons why so many chemical compounds are necessary to regulate pest populations. However, the rapid change of agriculture systems during the 20th century makes it difficult to evaluate the effects of such potential regulation agents.

Outbreaks of pest mites on Moso bamboo (Phyllostachys pubescens) have occurred since the late 1980 's, and many bamboo forests have been lost in Fujian province, China (Zhang and Zhang 2000). We launched a Japan-China joint research initiative to restore Moso bamboo forests and have suggested that the pest outbreaks on bamboo were primarlity triggered by a change of bamboo cultivation from polyculture to monoculture, which inevitably decreased arthropod (both pest and natural enemy) diversity (Zhang et al. 2004a). Investigating such a phenomenon must provide us with important information on the short-term changes that occur during drastic change from polyculture to monoculture.

In this paper, we attempt to show what happens to the pest mite populations in bamboo plantations when the cultivation practice changes from polyculture to monoculture, and identify the key factors responsible for the pest outbreaks from the perspective of using bio-diversity to achieve sustainable pest management. We attempt to evaluate the effect of nursery plants on the predator-prey systems of Moso bamboo plantations and use a systems simulation approach to show how a "two-plants, two host 
specific pest species, single natural enemy" system attains stability.

\section{Materials and Methods}

The targeted spider mite pest species, S. nanjingensis, only occurs on Moso bamboo, $P$. pubescens (PP, hereafter), and is therefore, only distributed in China (Zhang 2000). S. miscanthi occurs on Chinese silvergrass, Miscanthus sinensis (MS, hereafter), which is distributed over Japan, China, Korea and Thailand (Sakagami et al. 2009). MS is a prime undercover component of polyculture moso bamboo forests (Zhang et al. 2004b). The phytoseiid predator T. bambusae, is a specialist predator of these two prey species, able to intrude into woven nests of Stigmaeopsis spp. and feed upon the mites inside (Saito 1986; Mori and Saito 2004). S. nanjingensis never reproduces on MS, and S. miscanthi never reproduces on PP (Zhang unpublished). These two species showed a typical Stigmaeopsis life type (Saito 1983) in which individuals live gregariously within the dense woven nests they construct over depressions on the leaf undersurface (Saito 1997; Zhang 2000).

Field survey

In order to understand the population dynamics of T. bambusae and its prey S. miscanthi on MS, we conducted a field survey in a mixed (MS, PP, unknown bamboo species and several tree species) forest in Fuzhou, China. We arbitrarily collected fifty leaves from each of 5 MS stands (250 leaves in total) at ca. 15 day intervals and examined them at the 
Fujian Institute of Plant Protection. The sampled leaves were observed under dissecting microscopes and the numbers and life stages of both prey and predatory mites were recorded. The survey was conducted from Apr. 2, 2001 to Apr. 2, 2002.

For comparison, we referred to a study by Zhang (2002) on the mite population dynamics on monocultured PP, conducted in Yongan, Fujian province, China from Sept. 261996 to Oct. 29, 1998. The sampling methods and observation procedures are shown in Zhang (2002).

\section{Simulation model}

In order to evaluate the factors causing the trends observed in the above two fields, we developed a system model which can simulate simultaneously "one predator - two prey" interactions on two host plant species, i.e. MS and PP sub-systems (Fig. 4).

The model consists of two distinct host plant subsystems, i.e. MS and PP. There was no compatibility in prey species between the host plants, such that $S$. nanjingensis occurs only on PP, and S. miscanthi only on MS. The predator, T. bambusae on the other hand, could eat both prey species by migrating between the two host plants at particular immigration success rates $\left(m_{p}\right.$ and $\left.m_{m}\right)$. Furthermore, we only considered two life stages for each prey and predator species (even though they actually have 5 stages). Although most previous predator-prey interaction models neglect the

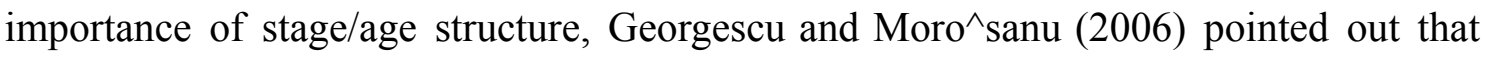
such a structure sometimes made dynamics stable. In the present model, we adopted two 
stages, one is non-reproductive (stage-1; immature females from egg to deutonymph) and the other reproductive (stage-2; mature females) in order to made the situation as realistic but as simple as possible. The flow diagram of the developed model is shown in Fig. 1. The definition of the parameters and values used in this simulation model are shown in Table 1, and the actual values and functional relationships between them are shown in Appendix 1.

We a priori assumed that a fate of predator-prey in monocltured PP (and also monocultured MS) was characterized periodical extinction of predator population and overshooting of prey population (see Figs. 2 and 3). In order to express this situation, we adopt an assumption that predator behavioral response (functional response) which describes how predators search and find their prey in response to prey population as "ratio-dependent manner", hereafter called as RD-model (Berryman 1999) other than Lotka-Volterra model (LV-model): How many prey a predator female feeds $\left(u_{i j}\right)$ in Table 1 , where, $i=p$, suffix of $u$, was PP, $i=m$ was MP, and $j=1$ was stage- 1 , and 2 was stage-2.) was a sigmoid function of "prey/predator" ratio (there is no sufficient experimental data for this function, such that we adopt an arbitrary function calculated from the maximum amount of prey eaten observed in Saito 1990, as shown in Appendix 1).

For other data concerning S. nanjingensis we referred to Zhang and Zhang (2000), for S. miscanthi from Sato et al. (2000), and for the predator, T. bambusae from Saito (1990), Zhang (2002) and Saito (unpublished). Several unknown parameters for prey 
species were replaced with data from closely related species, such as Stigmaeopsis longus (Saito) (Saito and Ueno 1979). Climatic conditions were assumed constant and all parameters were fixed as under $25 \pm 1^{\circ} \mathrm{C}$, favorable humidity (50-80\% r.h.) and no rain conditions. Furthermore, the MS and PP host plants were considered to be infinitely abundant, such that there were no food limitations on these two prey species.

The model was defined as difference equations as follows (see Appendix 2):

$$
\begin{aligned}
& X_{i 1}(t+1)=\left(1-A_{i 1}(t)\right)\left(1-d_{i}(t)\right) X_{i 1}(t)+F_{i}\left(X_{p 2}, X_{m 2}\right)\left(1-A_{i 2}(t)\right) B_{i}(t) \\
& X_{i 2}(t+1)=\left(1-A_{i 1}(t)\right) d_{i}(t) X_{i 1}(t)+F_{i}\left(X_{p 2}, X_{m 2}\right)\left(1-A_{i 2}(t)\right) \\
& Y_{i 1}(t+1)=\left(Y_{i 1}(t)-P_{i 1}(t)-L_{i 1}(t) X_{i 1}(t)\right)\left(1-d^{\prime}{ }_{i}(t)\right)+\left(Y_{i 2}(t)-P_{i 2}(t)\right)\left(1-a_{i 2}{ }^{\prime}(t)\right) b_{i}{ }^{\prime}(t) \\
& Y_{i 2}(t+1)=\left(Y_{i 1}(t)-P_{i 1}(t)-L_{i 1}(t) X_{i 1}(t)\right) d^{\prime}{ }_{i}(t)+\left(Y_{i 2}(t)-P_{i 2}(t)\right)\left(1-a_{i 2}^{\prime}(t)\right) \\
& F_{p}\left(X_{p 2}, X_{m 2}\right)=\left(1-E_{p}(t)\right) X_{p 2}(t)+m_{m}(t) E_{m}(t) X_{m 2}(t) \\
& F_{m}\left(X_{p 2}, X_{m 2}\right)=\left(1-E_{m}(t)\right) X_{m 2}(t)+m_{p}(t) E_{p}(t) X_{p 2}(t) \\
& E_{i}(t)=\frac{e^{20 X_{i 2}(t) /\left(y_{i 1} / 3+y_{i 2}\right)-4}}{50+e^{20 X_{i 2}(t) /\left(y_{i 1} / 3+y_{i 2}\right)-4}} \\
& L_{i 1}(t)=10 r_{i 1} u_{i 1} \frac{e^{0.5\left(\left(Y_{i 1}-P_{i 1}\right) / X_{i 1}-n_{i 1}\right)-6}}{1+e^{0.5\left(\left(Y_{i 1}-P_{i 1}\right) / X_{i 1}-n_{i 1}\right)-6}} \\
& L_{i 2}(t)=20 r_{i 2} u_{i 2} \frac{e^{0.3\left(\left(Y_{i 1}+3 Y_{i 2}\right) / F_{i}\left(X_{p 2}, X_{m 2}\right)-n_{i 2}\right)-4}}{2+e^{0.3\left(\left(Y_{i 1}+3 Y_{i 2}\right) / F_{i}\left(X_{p 2}, X_{m 2}\right)-n_{i 2}\right)-4}} \\
& P_{i j}(t)=\frac{Y_{i j}(t)}{Y_{i 1}(t)+3 Y_{i 2}(t)} L_{i 2}(t) F_{i}\left(X_{p_{2}}, X_{m 2}\right) \\
& A_{i 1}(t)=\left\{\begin{array}{cc}
-0.014 L_{i 1}(t)+0.14 & \text { if } L_{i 1}(t)<10 \\
0 & \text { if } L_{i 1}(t)>10
\end{array}\right. \\
& A_{i 2}(t)=\left\{\begin{array}{ccc}
-0.0034 L_{i 2}(t)+0.095 & \text { if } & L_{i 2}(t)<20 \\
0.027 & \text { if } & L_{i 2}(t)>20
\end{array}\right.
\end{aligned}
$$


$B_{i}(t)=\left\{\begin{array}{cl}0 & \text { if } L_{i 2}(t)<0.45 \\ 0.427 L_{i 2}(t)-0.192 & \text { if } 0.45<L_{i 2}(t)<4.22 \\ 1.61 & \text { if } L_{i 2}(t)>4.22\end{array}\right.$

where $i=p(i=m)$ was on PM (MM), and $j$ was age stage ( 1 or 2$)$.

We intended to highlight the importance of predator-prey interactions in complex, broad-scale fields (like bamboo forests) where predator searching efficiency must decrease considerably with lowered prey density per predator (Gols et al. 2005). In order to introduce such a factor into the model, we provided minimum prey-predator ratio values (predation success variables) under which predators were unable to catch any prey. This minimum value expressed the difficulty for predators to capture prey under low prey density conditions in broad-scale fields: the predation success variables $\left(n_{p j}\right.$ and $n_{m j}$ ) were defined as the lowest prey/predator ratio at which predators can take (capture) prey. We arbitrarily moved from the initial values $\left(n_{p j}\right.$ or $\left.n_{m j}=0\right)$ to a high value. Through these parameters, the area effect $(\approx$ dilution effect $)$ that must greatly decrease predation efficiency in broad-scale fields can be expressed.

The other undetermined parameters, immigration success rates from MS to PP $\left(0 \leq m_{p} \leq 1\right.$ and from PP to MS $\left(0 \leq m_{m} \leq 1\right)$ between the two host plants were defined as the ratio of "successful predator immigration to one host plant" / "all emigrated predators from the other plant". Note that how many predators emigrating from a host plant system was separately determined as dispersal rates that were a function of the prey/predator ratio in each system (we used the ratio observed in Phytoseiulus persimilis by Saito et al. 1996).

This simulation model was thus intended to identify any undetermined effects of the 
predation success parameters $\left(n_{p j}\right.$ and $\left.n_{m j}\right)$ and of the predator migration success rates between PP and MS ( $m_{p}$ and $\left.m_{m}\right)$ under field conditions on the stability of the overall system.

The predator-prey simulation system model was developed using the software, Mathematica ver. 6.0 (Wolfram Research) on a Macintosh computer (G5, Apple Co. Ltd.). We term the model "TOS (after its developers Tsuji, Ogawa and Saito) hereafter.

\section{Results}

Field survey

The one-year population dynamics of $S$. miscanthi and T. bambusae (all stages were lumped) on MS in a polyculture bamboo forest are shown in Fig. 2. The S. miscanthi population fluctuated periodically and T. bambusae population also showed similar fluctuations with a short time lag. This appeared to be a typical oscillating predator-prey interaction pattern (Lotka 1925; Volterra 1926). On the other hand, there was no synchronization in the fluctuation patterns between S. nanjingensis and T. bambusae in monoculture PP forests (Fig. 3 from Zhang 2002).

In order to know more about the above two dynamics, we plotted the temporal population density of the predator (T. bambusae, on the vertical axis) to the population density of prey mite (S. miscanthi or S. nanjingensis, on the horizontal axis) in Fig. 4. The track of temporal changes of the predator and prey densities showed no visible trend in the monoculture PP systems (Fig. 4). On the other hand, the track was always positioned near a line showing a constant prey to predator ratio in the MS systems (Fig. 4). This means that the interaction forms a kind of limit cycle, though the 
cycle showed some distortion. In other words, we expected density dependent factor(s) in predator-prey dynamics on MS systems, but no such factor(s) in monocultured PP systems, meaning that the predator-prey systems on MS in mixed forests were to some extent stabilized, but those on PP in monoculture plantations were not.

Simulation

It is usually difficult to define systems stability strictly in simulations, such that we tentatively defined a "stable state" as when the predator-prey systems continued at least 1100 days (more than 3 years) except for the case when both predator and prey populations increased indefinitely (both overshooting, see later).

We first simulated what patterns were observed by simulations using undetermined parameters of various values (about predation success, $n_{\mathrm{ij}}$ and immigration success, $m_{\mathrm{i}}$ ). The following four typical patterns were obtained from 1100-day simulations (Fig. 5):

Type 1: The prey and predator populations both decreased to nearly zero (regardless of whether they became extinct or not).

Type 2: The prey and predator populations both decreased to nearly zero. After the predator population became extinct, the prey population overshot.

Type 3: The prey and predator populations first decreased gradually. Then they continued at low levels for a long period in a more or less stable manner.

Type 4: The prey and predator populations increased gradually for a long period.

As will be discussed later, although these types do not always differ from each other during longer-scale simulations, we observed how these patterns appear in response to 
the two kinds of undetermined parameter during a period restricted to 1,100 days.

\section{Simulation 1}

When the predator immigration success rates from one sub-system to the other, $m_{p}$ and $m_{m}$ were set to 0 , how the predation success values, $n_{m j}$ (in MS) and $n_{p j}$ (in PP) affected the simulation result was observed.

In most combinations of $n_{m 1}$ and $n_{m 2}$ (or $n_{p 1}$ and $n_{p 2}$ ), a type 2 pattern was observed (Fig. 6). A type 1 pattern, which suggested predators successfully suppressed prey populations during the 1100 days, was only observed in PP when $n_{m 2}=2$ and $n_{m 1}=1 \sim 6$. Type 3 patterns were rarely observed in this simulation, although there were three cases at $n_{m 2}=5$ and $n_{m 1}=2 \sim 3$ in PP. Furthermore, if $n_{m}$. or $n_{p}$ was sufficiently high, type 4 patterns where predators found it difficult to get prey were observed.

\section{Simulation 2}

We then simulated whether cases exist where predator and prey populations reach a stable state for particular parameter values at which both the isolated systems in simulation 1 showed a type 2 pattern. For this purpose, we assumed the values $n_{m 1}, n_{m 2}$, $n_{p 1}$ and $n_{p 2}$ were constant at 4.5 (Fig. 6).

The results of simulation 2 suggest that if there are predator migrations between two plant sub-systems (meaning that the two plant systems are connected by predator migration), there are many conditions under which either system can reach a stable state, i.e. type 3 (Fig. 7). It was apparent that at middle values of $m_{p}=0.4 \sim 0.8$ and $m_{m}=$ $0.3 \sim 0.7$, both systems reached a type 3 pattern, meaning that predators regulate the prey populations at low densities and both populations continue at least for 1,100 days 
(Fig. 7).

\section{Discussion}

As stated previously, the stable state in this simulation was conveniently defined from the population trends that occurred over 1,100 days, a period roughly equivalent to 3 years. We considered this a sufficient period for evaluating systems stability in field plantations, because PP foliation has a 2-year cycle (Zhang et al. 2000). However, whether or not the observed types are supportable theoretically is a different matter. Thus, we checked whether types 1-4 would result in different population trend patterns if the periods were of longer duration. As a result, we could confirm the following: Type 1 is synonymous with type 2 when the simulation period was prolonged (to 2,000 days). Predator and prey populations in type 1 were maintained at very low densities, but the predator population finally became extinct and prey population overshot. However, it is unrealistic to expect such low-density predator-prey interactions to continue for more than 1 year, because unexpected factors such as adverse temperatures and/or rain must influence long-term survival under field conditions. As such, we may consider type 1 to be a pattern of both predator and prey extinction. On the other hand, we may say that type 3 is a stable state pattern in which the predators can regulate the prey population well, even though it is also synonymous with type 2 when the simulation period is sufficiently long (more than 2,000 days).

Both theoretically and practically speaking, we have ample evidence from observing predator-prey interactions in closed or experimental systems, that prey populations first become extinct through predator over-exploitation, then the predator populations go 
extinct through starvation (Fujita et al. 1979; Kuno 1987; Saito 1996). However, we observed no such pattern in the present simulation (remember that type 1 is synonymous with type 2 for long periods), partly because of the two assumptions that strongly decrease the chances of predator exploitation (RD-model and $n_{p j}$ and $n_{m j}$ ). As supposed from the "life-dinner principle" (Dawkins and Krebs 1979), predation does not always lead to prey extinction in nature. This discrepancy in presupposition is related to habitat complexity and/or the prey-density dependent changes in predation success (prey finding opportunities) for predators (Huffaker et al. 1963). As such, in addition to the predators' response to number of prey per predator $\left(=u_{p j}\right.$ and $u_{m j}$, which are the behavioral response outputs of the predator against the prey as in Appendix 1), we introduced parameters which change the minimum ratio of the number of prey per predator at which predator can capture prey.

As shown experimentally by Gause (1934), if there are refuges for prey that are difficult for predators to invade, some prey will always escape predation, but predators will become locally extinct. It is reasonable to assume that such a mechanism also exists in moso bamboo and Chinese silvergrass plantations as well, as both are huge in comparison to the scale of the animal focused on. Furthermore the two Stigmaeopsis mite species examined during this study construct densely woven nests on the leaf undersurface. Because most predators use nests as clues when searching for prey, the woven nests have a strong hindering effect after suffering predation (Saito et al. 2008), such that these two prey species have a strong ability, as a population-wide effect, to lower predation risks during low-density periods after predators have decimated their 
populations. The sheer scale of the vegetation types concerned, as well as the prey species peculiar ability to avoid predation in the manner mentioned above, suggest that at the local level at least, the extinction of predators through starvation is more frequent than the extinction of prey through predation, in both bamboo forests (Fig. 3) and silvergrass vegetation alike.

Gause's (1934) classic study also showed that the periodic immigration of prey from outside makes predator-prey systems stable, although such prey immigration could not be assumed in either of the present systems. Conversely, the periodic immigration of predators from outside, i.e. from other plants, is realistic and allows the systems to attain stability. As such, our simulations showed that a "two-plant / two host specific pest species / single natural enemy" system can often attain stability through predator migration between two plant species. Although our model was too simplistic to simulate the actual dynamics of mite populations in Chinese bamboo forests, these findings are believed to partly explain the phenomenon that has occurred there: a change in bamboo cultivation practice from polyculture to monoculture, with the subsequent elimination of all Chinese silvergrass vegetation, may have triggered the S. nanjingensis outbreaks.

The most important concern of the present study is to show how a certain mechanism can provide relative stability to several mite species. The system consisting of one common predator and two prey species on different plants has not been considered in previous studies on predator-prey interactions, though the importance of such a system has been pointed out empirically. We have shown that the conservation of such diversified systems must contribute to the stability of bio-systems and simultaneously 
contribute to the biological control of pest species by using endemic natural enemies. In other words, we could prove that bio-diversity is an effective regulator of pests.

From a theoretical perspective, Tansky (1978) and Matsuda et al. (1985) showed that predator-prey systems under which predators can switch from one prey species to another in a prey-density dependent manner easily attain a stable state. In these studies, a single predator has the ability to switch between two prey species depending upon respective prey density. In the present simulation model, we considered that predators move between two host plants where different prey species occur, depending upon the densities of the prey species. In other words, we assumed that there is no way for the predator to switch prey species on a single host plant species, and they should move to the other host plant to get access to the other prey species. However, the situations in the present model are thought to be analogous to the models of Tansky (1978) and Matsuda et al. (1985). Although we did not mathematically analyze the conditions under which the present systems attain stability and did not adopt a definition of stable state in the strict sense, our results are still thought to provide a practical example of their theories.

\section{Acknowledgements}

We thank Drs. J-Z Lin, Y. Kamimura, T. Sakagami, Y. Sato, K. Ito and Mr. J. Jei for their valuable comments and suggestions. This study was partly supported by grant-in-aid B-17370005 for scientifc research from JSPS and MEXT through Special Coordination Funds for the Promoting of Science and Technology, entitled "Sustainability Governance Project." 


\section{References}

Beers EH, Riedl H, Dunley JE (1998) Resistance to Abamectin and Reversion to susceptibility to Fenbutatin Oxide in Spider Mite (Acari: Tetranychidae) populations in the pacific northwest. J Econ Entomol 91: 352-360

Berryman AA (1999) The theoretical foundations of biological control. In: Hawkins BA,Cornell HV (eds) Theoretical approaches to biological control. Cambridge Univ. Press, Cambridge, pp 3-21

Carson R （1962） Silent Spring. Houghton Mifflin, Boston

Colborn T, Dumanoski D, Myers JP (1996) Our Stolen Future, Dutton, New York Dawkins R, Krebs JR (1979) Arms races within and between species. Proc R Soc Lond B 205: 480-512

Flexner JL, Westigard PH, Hilton R, Croft BA (1995) Experimental Evaluation of Resistance Management for twospotted spider mite (Acari: Tetranychidae) on Southern Oregon Pear: 1987-1993. J Econ Entomol 88:1517-1524

Fujita K, Inoue T, Takafuji A (1979) Systems analysis of an acarine predator-prey system. I. Res Popul Ecol 21: 105-109

Gause GF (1934) The struggle for existence. Baltimore, MD: Williams \& Wilkins.

Georgescu P, Moro.sanu G (2006) Global stability for a stage-structured predator-prey model. Math Sci Res J 10: 214-226

Gols R, Bukovinszky T, Hemerik L, Harvey JA,Van Lenteren JC, Vet LE (2005) Reduced foraging efficiency of a parasitoid under habitat complexity: implication for population stability and species coexistence. J Anim Ecol 74:1059-1068 
Huffaker CB, Shea KP, Herman SG (1963) Experimental studies on predation: complex dispersion and levels of food in an acarine predator-prey interaction. Hilgardia 34: 305-329

Kuno E (1987) Principles of predator-prey interaction, theoretical, experimental, and natural population systems. Adv Ecol Res 16: 249-337

Lotka AJ (1925) Elements of physical biology. Baltimore, Williams \& Wilkins Co.

Matsuda H, Kawasaki K, Shigesada, N, Teramoto E, Ricciardi LM (1985) Evolutionary and ecological stability of prey-predator systems with predator switching. In:

Teramoto E and Yamaguti M (eds), Mathematical topics in population bilogy, morhogenesis and neurosciences, Springer-Verlag, Berlin, pp 172-181

Mori K, Saito Y (2004) Nest size variation reflecting anti-predator strategies in social spider mites of Stigmaeopsis (Acari: Tetranychidae). Behav Ecol Sociobiol 56: 201-206 Osborne LS, Barrett JE (2005) Banker plants can be used to rear natural enemies to help control greenhouse pests. Ornamental Outlook, September 2005: 26-27. (http://mrec.ifas.ufl.edu/lso/DOCUMENTS /BANKERFoliage.pdf)

Ruberson J, Nemoto H, Hirose Y (1998). Pesticides and conservation of natural enemies in pest mngement. In: Barbosa P (ed) Conservation Biological Control, Elsevier, Amsterdam, pp 207-220

Saito Y (1983) The concept of "life types" in Tetranychinae. An attempt to classify the spinning behaviour of Tetranychinae. Acarologia 24: 377-391

Saito Y (1986) Biparental defence in a spider mite (Acari: Tetranychidae) infesting Sasa bamboo. Behav Ecol Sociobiol 18: 377-386 
Saito Y (1990) Life history and food habit of Typhlodromus bambusae Ehara, a specific predator of Schizotetranychus celarius (Banks) (Acari: Phytoseiidae, Tetranychidae). Exp Appl Acarol 10: 45-51

Saito Y (1997) Sociality and kin selection in Acari. In: Choe JC, Crespi BJ (eds) The Evolution of Social Behaviour in Insects and Arachnids, Cambridge Univ Press, Cambridge, pp $443-457$

Saito Y, Chittenden AR, Mori K, Ito K, Yamauchi A (2008a). An overlooked side effect of nest scattering behavior to decrease predation risk (Acari; Tetranychidae, Stigmaeidae). Behav Ecol Sciobiol 63: 33-42

Saito Y, Tsuji N, Chittenden AR (2008b) Sustainable pest management and moso bamboo forest conservation -A preliminary report-. Proceedings of ICSA2008: 309-316 Saito Y, Ueno J (1979) Life history studies on Schizotetranychus celarius (Banks) and Aponychus corpuzae Rimando as compared with other tetranychid mite species (Acarina: Tetranychidae). Appl Entomol Zool 14: 445-452

Saito Y, Urano S, Nakao H, Amimoto K, Mori H (1996). A simulation model for predicting the efficiency of biological control of spider mites by phytoseiid predators. 1 . The model. Jpn J Appl Entomol Zool 40: 103-111 (in Japanese with English summery) Sato Y, Saito Y, Mori K (2000) Patterns of reproductive isolation between two groups of Schizotetranychus miscanthi Saito (Tetranychidae: Acari) showing different male aggression traits. Appl Ent Zool 35: 611-618

Tansky M (1978) Switching effect in prey-predator system. J theor Biol 70:263 -271

Tsagkarakou, A., M. Navajas, J. Lagnel, J. Gutierrez, and N. Pasteur. (1996). Genetic 
variability in teranychus urticae (Acari: Tetranychidae) from Greece: Insecticide resistance and Isozymes. J Econ Entomol 89: 1354-1358.

Tscharntke T, Bommarco R, Clough Y, Crist TO, Kleijn D, Rand TA, Tylianakis J M, van Nouhuys S, Vida S (2007) Conservation biological control and enemy diversity on a landscape scale. Biological Control 43: 294-309

Volterra V (1926) Variazioni e fluttuazioni del numero d'individui in specie animali conviventi. Mem R Accad Naz dei Lincei SerVI, vol. 2 Weeden CR, Shelton AM, Hoffman MP (2008) Biological Control: A Guide to Natural Enemies in North America. http:/www.nysaes.cornell.edu/ent/ biocontrol/new.html Zhang YX (2002) Studies on factors causing outbreaks of pest mites in bamboo forests in Fujian, China. Doctoral Dissertation in Hokkaido University.

Zhang YX, Zhang QZ (eds) (2000) Biology and control of bamboo mites in Fujian. Syst Appl Acarol Soc Special Publ 4, London

Zhang YX, Zhang ZQ, Tong LX, Liu QY, Song MG (2000) Causes of pest mite outbreaks in bamboo forests in Fujian, China: analyses of mite damage in monoculture versus polyculture stands. In: Zhang YX, Zhang ZQ (eds) Biology and control of bamboo mites in Fuhian. Syst Appl Acarol Spec Publ 4, London, pp 93-108

Zhang YX, Saito Y, Ji J, Lin JZ (2004b) The cause of the decrease of population dynamic of Typhlodromus bambusae Ehara in moso bamboo forest. Entomol J East China 13: 55-61.

Zhang YX, Zhang ZQ, Saito Y, Liu QO, Ji J (2004a) On the causes of mite pest 
outbreaks in mono- and poly-cultured moso bamboo forests. Chinese J Appl Ecol 15: 1161-1165 (in Chinese with English abstract). 


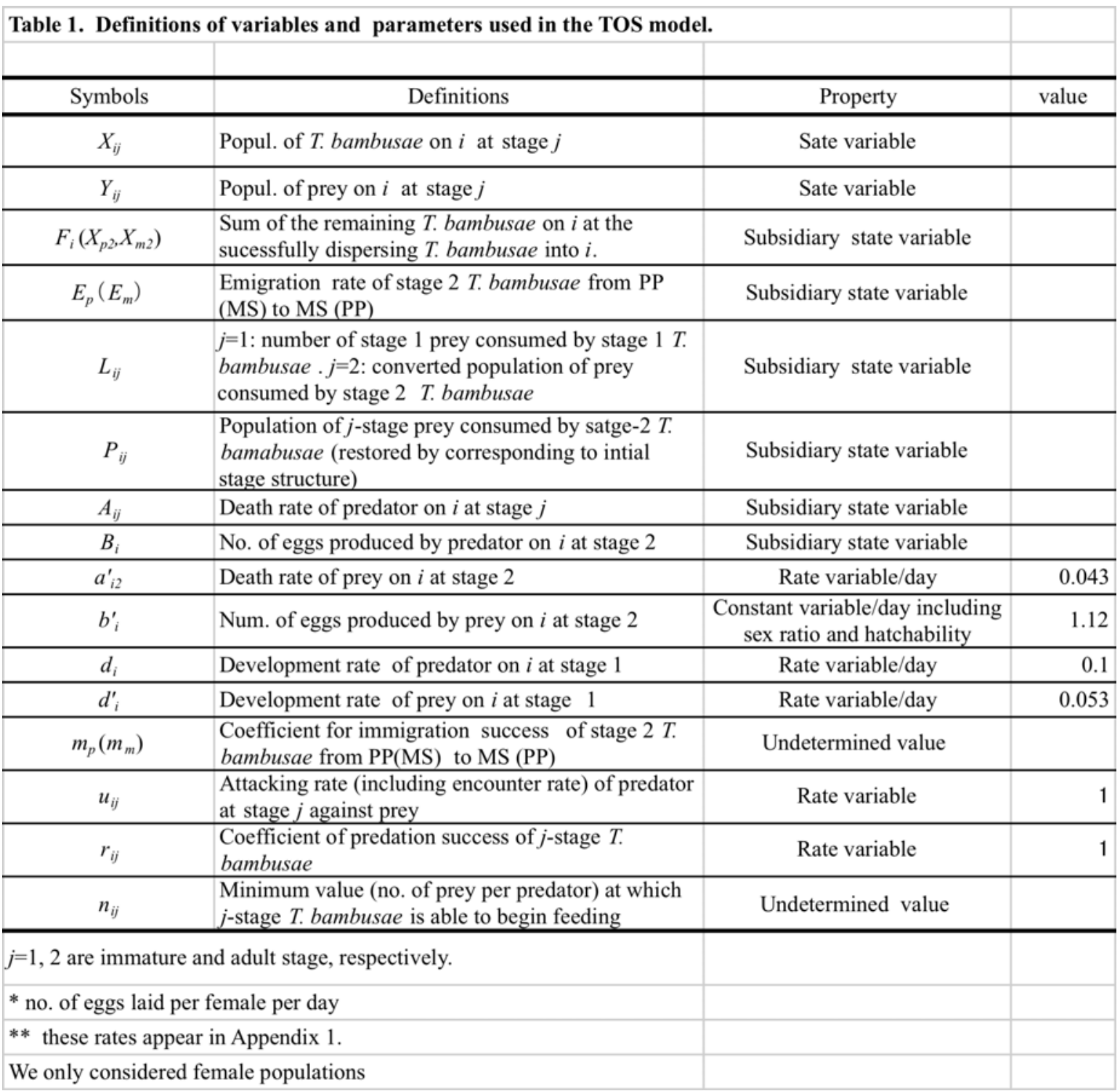

Figure legends:

Fig. 1. Brief flow diagram of TOS model.

Fig. 2. Population dynamics of S. miscanthi and T. bambusae on M. miscanthi in a 
polyculture bamboo forest.

Fig. 3. Population dynamics of $S$. nanjingensis and T. bambusae on P. pubescens (from Zhang 2000) in a monoculture bamboo plantation.

Fig. 4. Temporal change of relationship between prey and predator densities. PP, $S$. nanjingensis and T. bambusae on monocultured P. pubescence; MS, S. miscanthi and T. bambusae on $M$. sinensis growing in polycultured (mixed) bamboo forest.

Fig. 5. Four patterns obtained by the present simulation model.

Fig. 6. Results of simulation 1 when there is no predator migration. PP, $S$. nanjingensis and T. bambusae on P. pubescence, MS, S. miscanthi and T. bambusae on $M$. sinensis.

Fig. 7. Results of simulation 2 when predator immigration success varied. The other explanations are the same as Fig. 6. 


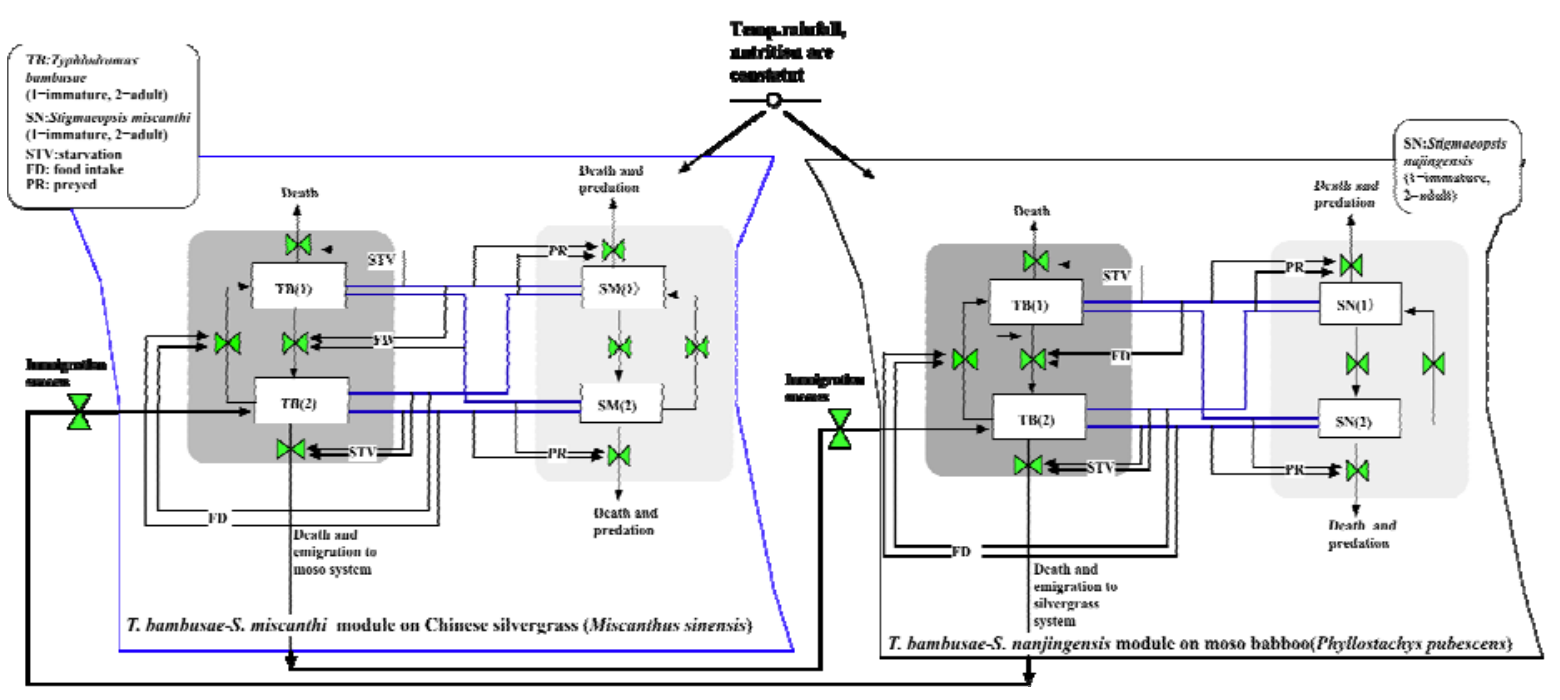

Fig. 1

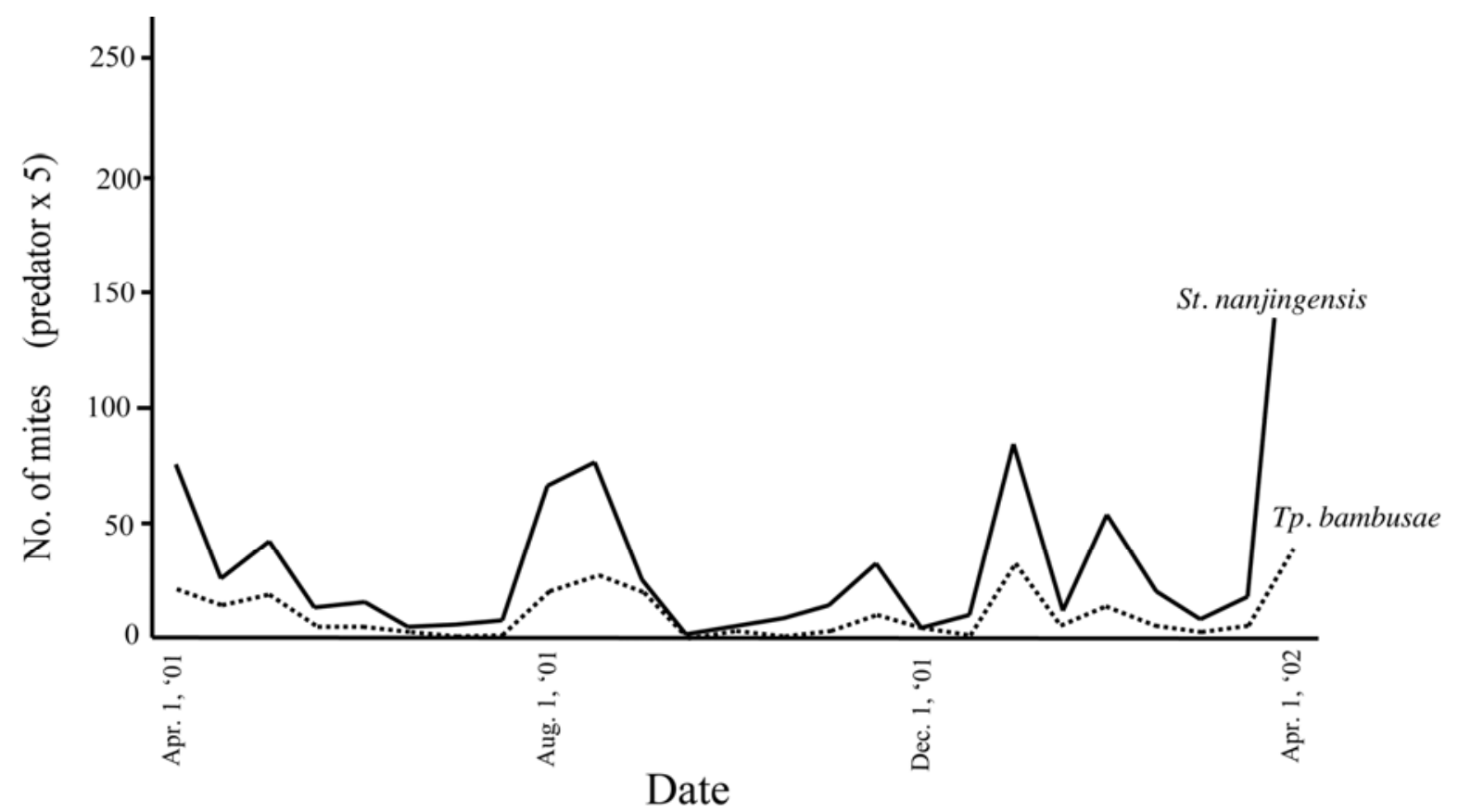

Fig. 2 


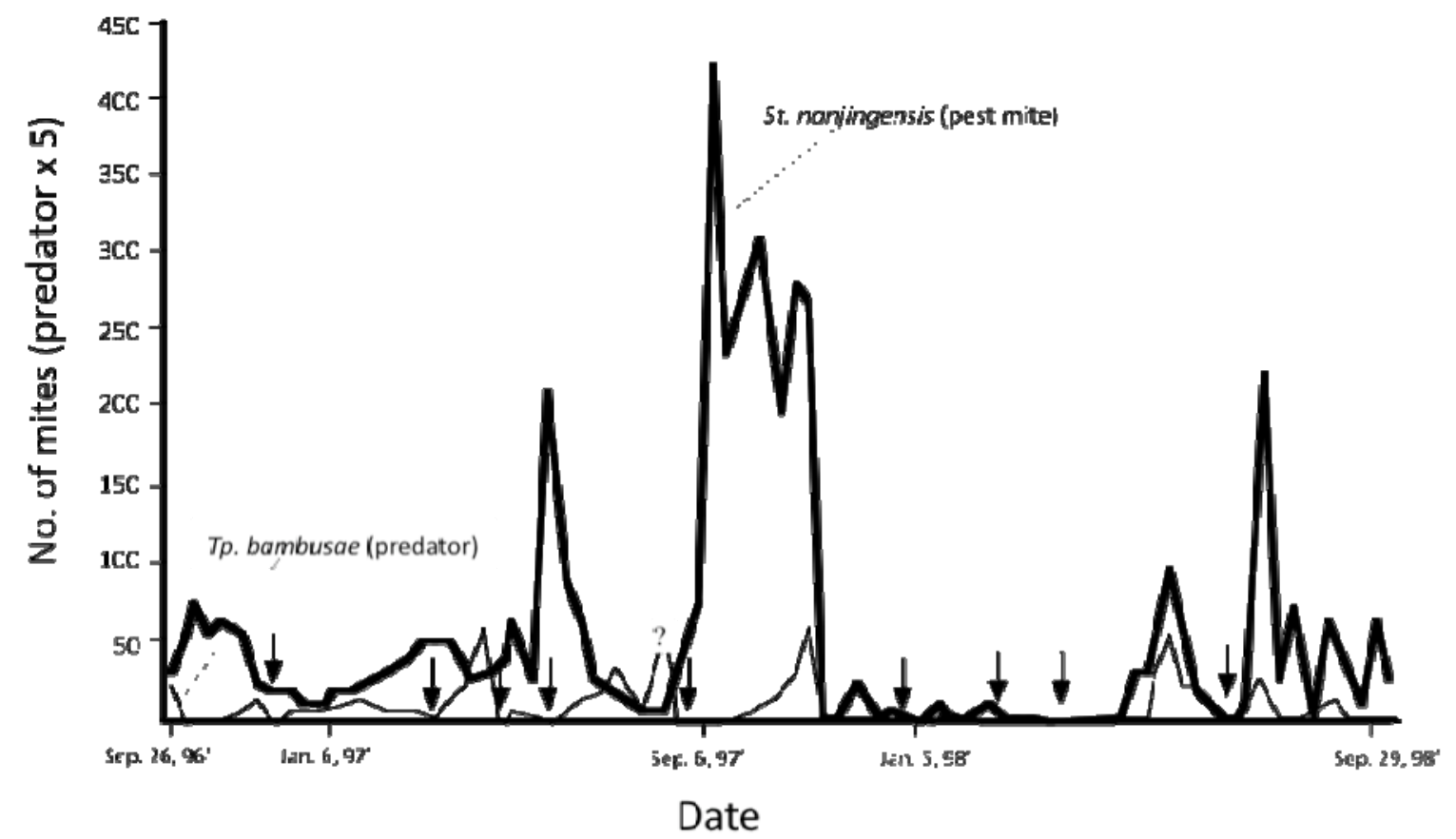

Fig. 3

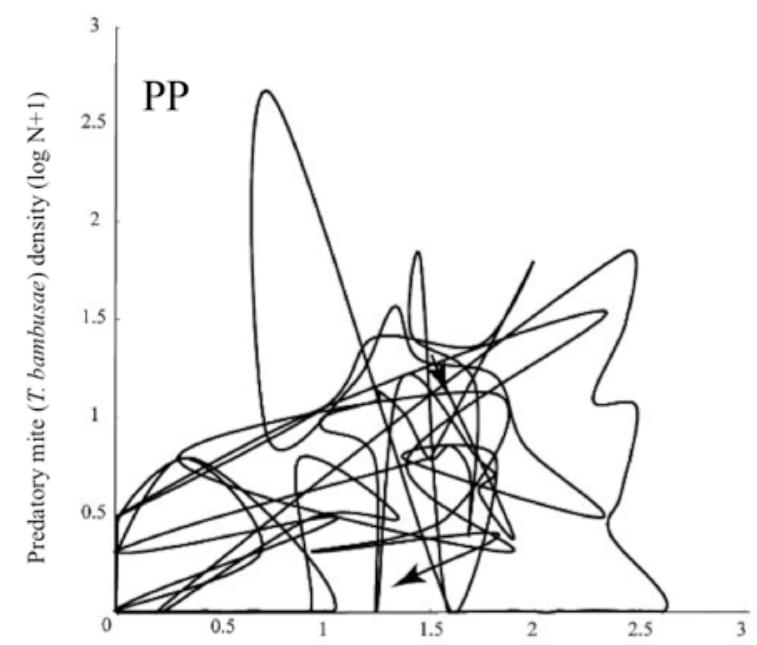

Prey mite (S. nanjingensis) density $(\log \mathrm{N}+1)$

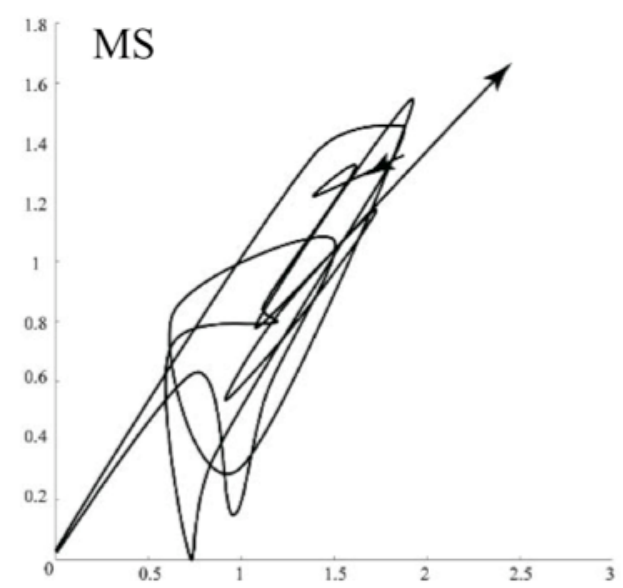

Prey mite (S. miscanthi) density $(\log \mathrm{N}+1)$

Fig. 4 

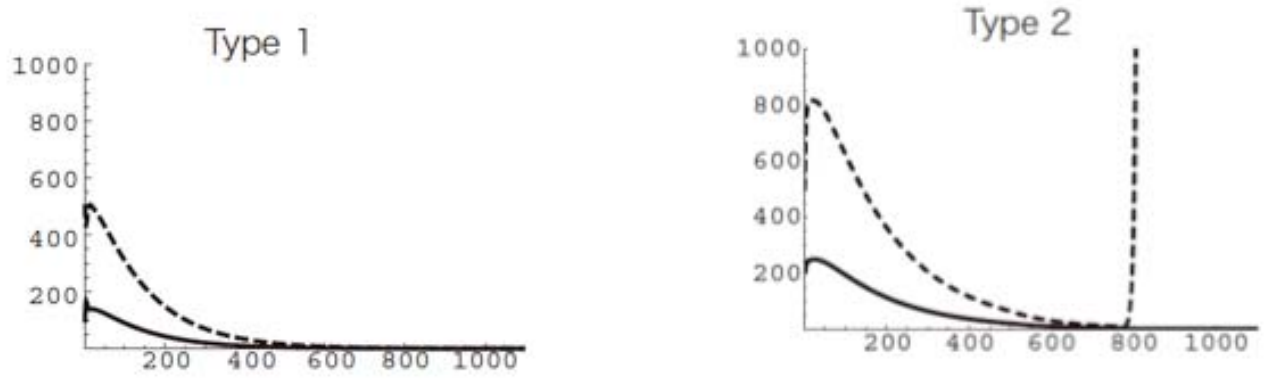

Type 3
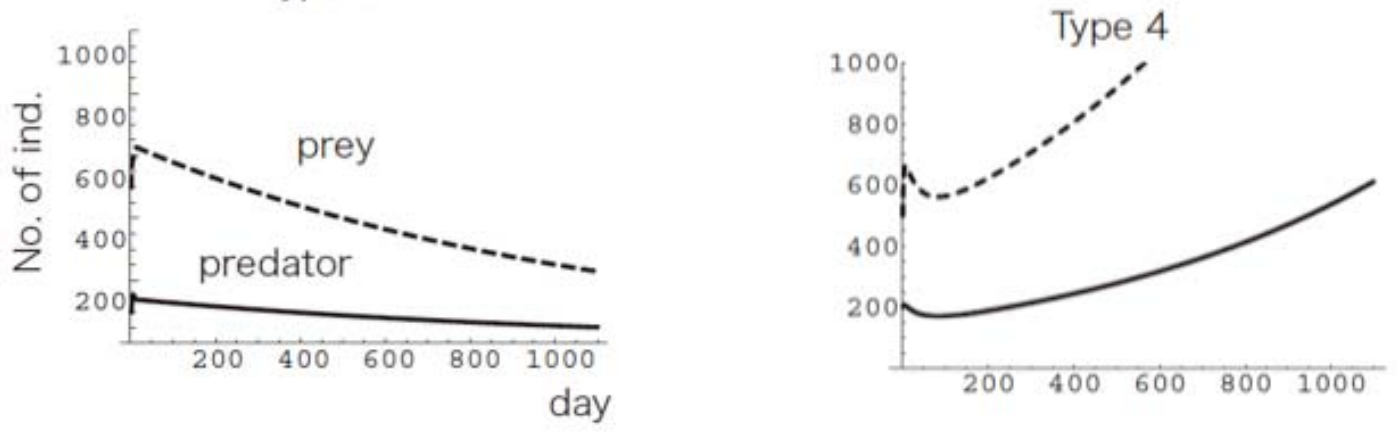

Fig. 5

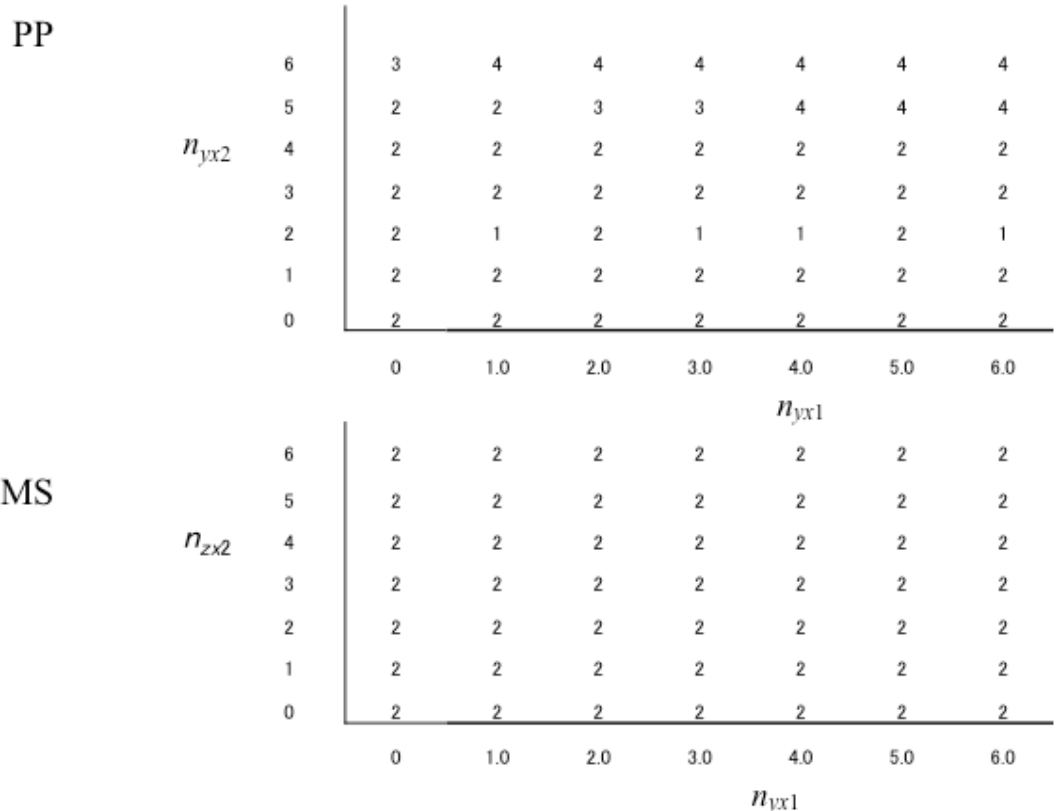

Fig. 6 


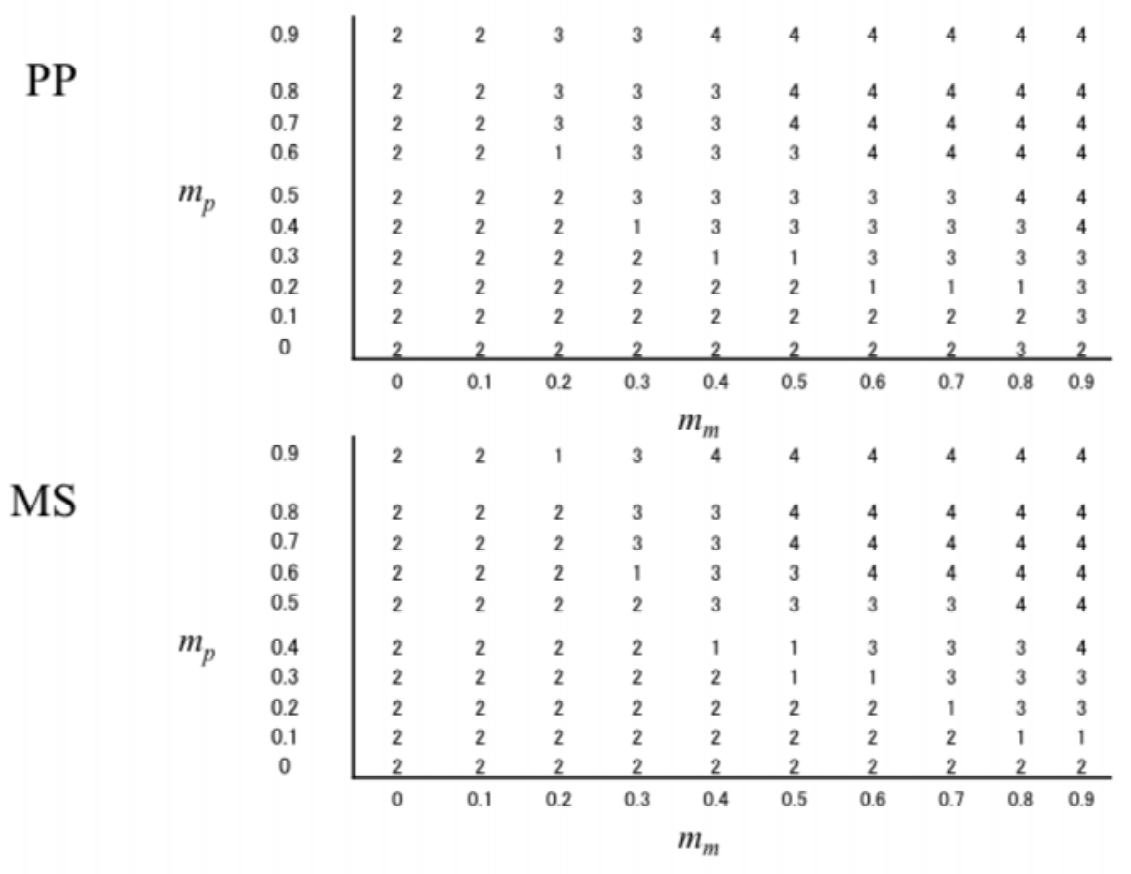

Fig. 7 

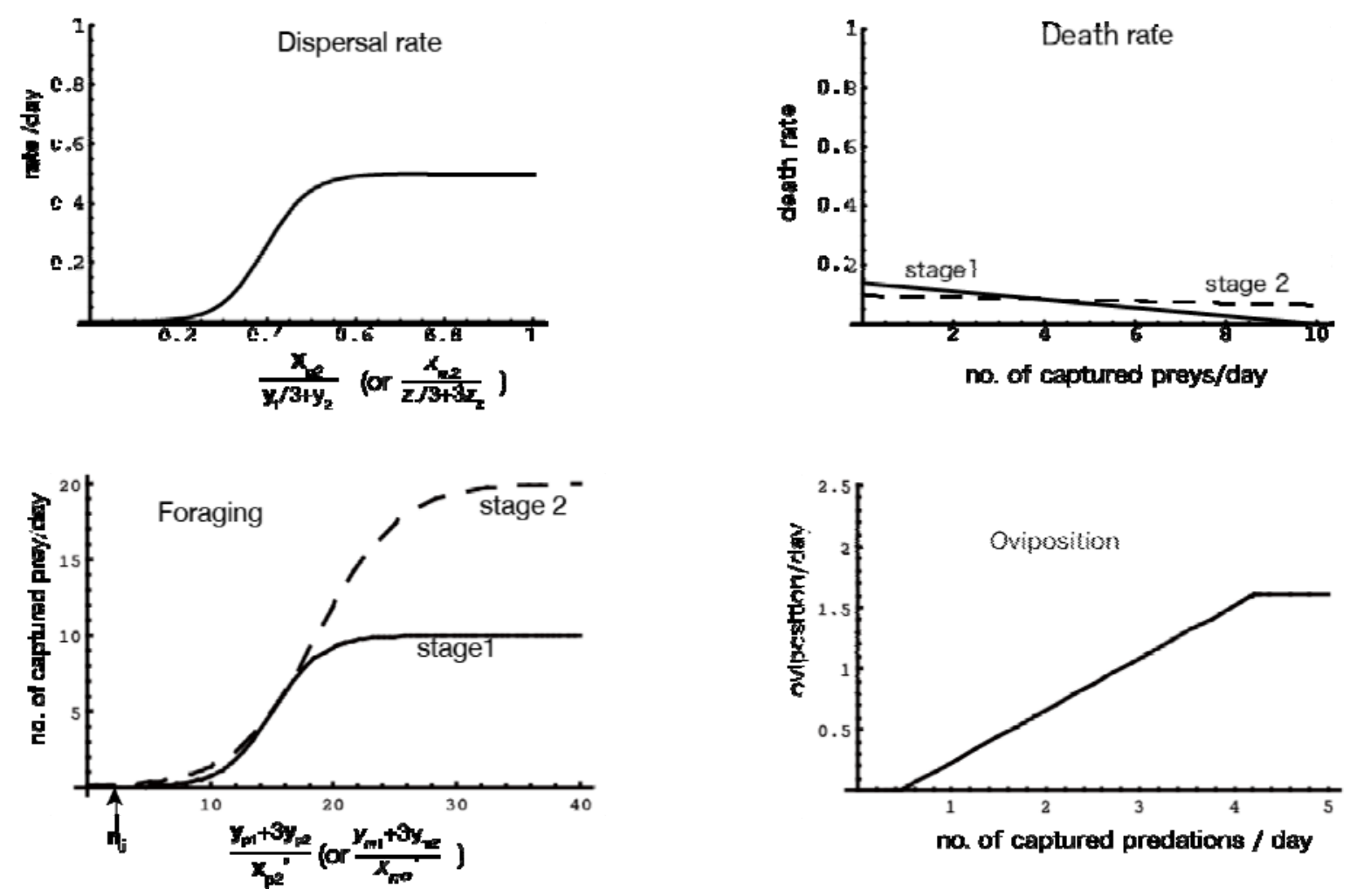

Appendix 1. Several important functions which determined parameter values.

Bamboo (PP)

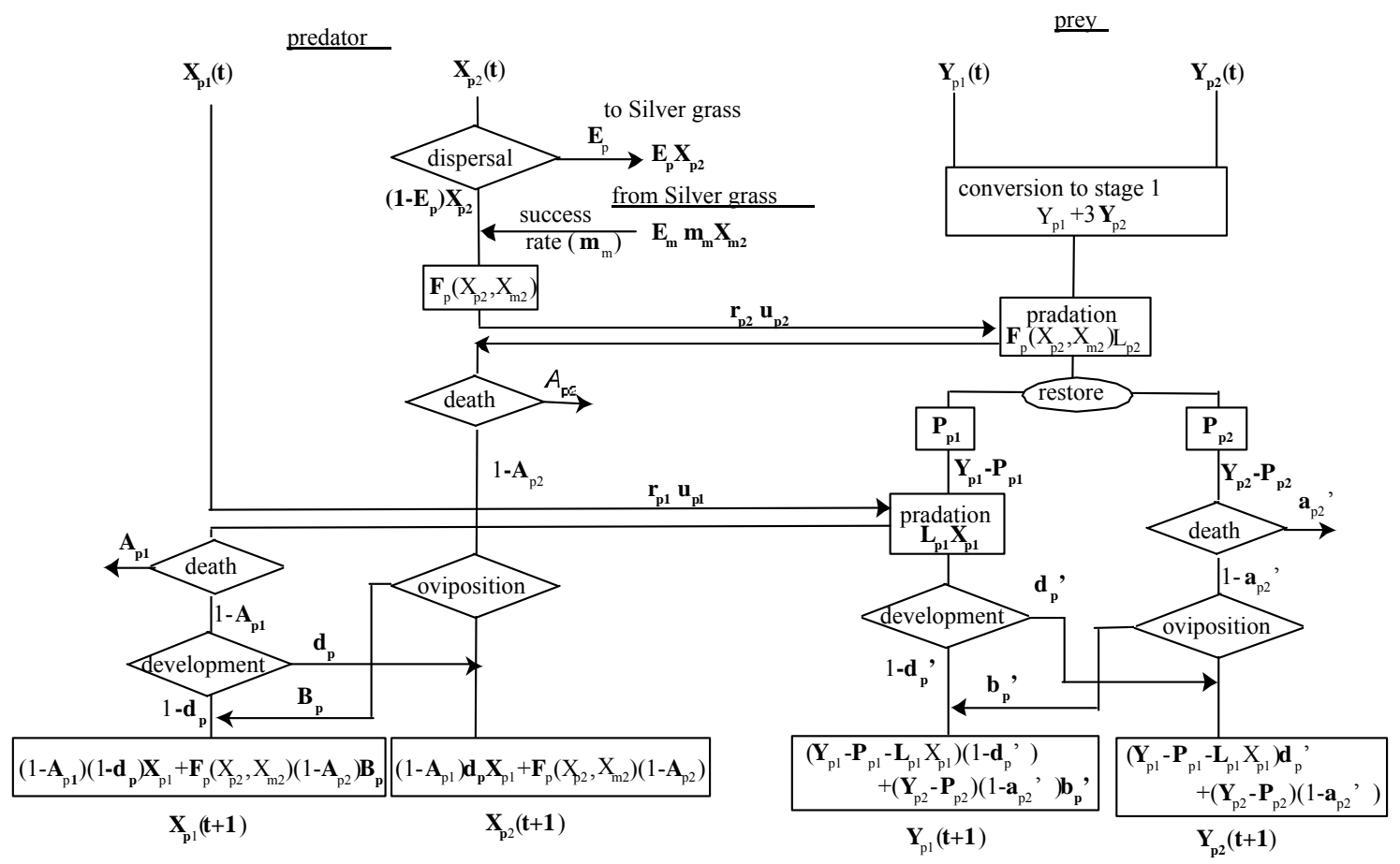

Appendix 2. Detaled flow diagram of model of PP subsystem (MS subsystem is almost the same other than the parameter symbols in Table 1). 